\title{
O SENTIDO E OS SIGNIFICADOS DO ENSINO DE MATEMÁTICA EM PROCESSOS DE EXCLUSÃO E DE INCLUSÃO ESCOLAR E SOCIAL NA EDUCAÇÃO DE JOVENS E ADULTOS
}

\author{
The Sense and the meanings of mathematics education in cases of exclusion and \\ inclusion school and social at young and adult education.
}

Ana Maria Sgrott Rodrigues ${ }^{1}$ Rosália M. R. de Aragão ${ }^{2}$

\begin{abstract}
RESUMO: A presente investigação se configura em termos qualitativos de pesquisa como um estudo de caso dos alunos de uma escola estadual integrante do programa especial de Educação de Jovens e Adultos - EJA. Tais alunos estavam matriculados na $3^{\mathrm{a}}$ e na $4^{\mathrm{a}}$ etapas do programa, cujo formato curricular corresponde às quatro últimas séries do Ensino Fundamental de $5^{\mathrm{a}}$ a $8^{\mathrm{a}}$ séries, cuja operacionalização concentra conhecimento,

Matemática, objetivando produzir outros sentidos, relações e nexos que respondam ao 'como' e ao 'por que' os elementos de análise destacados contribuem e incidem no processo de inclusão ou exclusão escolar. As análises por nós procedidas possibilitam evidenciar os termos da indiferença escolar e do despreparo docente quer pela desconsideração da história do alunado quer pela visão distorcida de "currículo justo" e "igualdade de oportunidades" na comparação com os alunos legalmente ditos vinculados ao "ensino regular".
\end{abstract} espaço e tempo uma vez que cada etapa é desenvolvida em um ano letivo. A escola escolhida se localiza em área geográfica de 'ocupação' cuja comunidade vive na condição de exclusão social, justamente no entorno de duas universidades públicas. Os jovens e adultos originados desse contexto, que estudam nessa escola, vivenciaram uma trajetória escolar marcada por impedimentos de estudar, reprovações e interrupções escolares que os impediram de concluir o Ensino Fundamental. Por essas razões, nos propusemos investigar para conhecer, no âmbito do ensino da Matemática, elementos que contribuem para a (re)inclusão escolar com sucesso desses alunos, bem como elementos que acabam por incidir na sua (re)exclusão escolar, um fenômeno que retroalimenta o processo inevitável de exclusão social desses alunos. Para tanto, assumimos a construção de uma trama narrativa relativa ao contexto dessa escola, envolvendo e interagindo dialogicamente os seus sujeitos nesta pesquisa, quais sejam, alunos, professores e funcionários da escola. Consideramos suas historicidades e suas interpretações dos eventos pedagógicos vividos por eles em relação ao ensino de

Palavras-chave: educação matemática, processos de exclusão e inclusão escolar e social, educação de jovens e adultos.

\begin{abstract}
This investigation is framed in terms of qualitative research as a case study of students in a public school member of the special program of Youth and Adults - EJA. These students were enrolled in the $3 \mathrm{rd}$ and 4 th stages of the program, whose curriculum format corresponds to the last four grades, from 5 th to 8 th grades, whose operation is concentrated knowledge, space and time as each step is developed in a school year.The chosen school is located in the geographic area of 'occupation' which the community lives in conditions of social exclusion, precisely in the vicinity of two public universities. Young and adults people this context, studying at the school, experienced a school career marked by impediments to study, school failures and interruptions that prevented them from completing the elementary school. For these reasons, we decided to investigate to learn under the teaching of mathematics, elements that contribute to inclusion in school
\end{abstract}

\footnotetext{
1 Mestre do Programa de Pós Graduação em Educação em Ciências e em Matemática - Universidade Federal do Pará anasgrott@ig.com.br

${ }^{2}$ Orientadora, Docente e pesquisadora do Programa de Pós Graduação em Educação em Ciências e em Matemática Universidade Federal do Pará - rosalia.aragao@uol.com.br
}

AMAZÔNIA - Revista de Educação em Ciências e Matemáticas V. 5 - n. 9 - jul. 20o8/dez. 20o8, V. 5 - n. 10 - jan 20o9/jun. 2009 37 
with success for these students, as well as elements that ultimately relate to school exclusion, a phenomenon that feeds back the inevitable process of social exclusion of these students. To this end, we assume the construction of a narrative plot on the context of the school, involving and interacting dialogically their subjects in this study, namely, students, teachers and school staff. Consider their histories and their interpretations of events experienced by teaching them about the teaching of mathematics, aiming to produce other meanings, relationships and connections that meet the 'how' and 'why' analysis elements contribute outstanding and concern the process inclusion or exclusion from school. Analyses proceeded possible for us to show the terms of the indifference of the school and teachers unprepared either by ignoring the history of the students either by distorted view of "curriculum fair" and "equal opportunities" in comparison with students told legally bound to "regular education".

Keywords: mathematics education, processes of exclusion and inclusion school and social, youth and adults education.

\section{INTRODUÇÃO}

A diversidade de nossas vivências profissionais no campo da educação em contextos onde se evidencia a exclusão social contribuiu para aguçar nossas percepções tanto em relação às implicações e aos impactos que a exclusão social promove quer no indivíduo quer nos grupos sociais, quanto em relação ao processo de exclusão escolar vivenciado por parte de muitos alunos, em virtude de serem reprovados múltiplas vezes pela escola, ou por se envolverem intensamente na luta pela sobrevivência.

$\mathrm{Na}$ esteira dessas idéias, buscamos orientar nossa reflexão para compreender a participação da educação, suas inserções e ocultações, nesses processos sociais, uma vez que perpassa e participa dessa dinâmica na relação que é estabelecida através da escola. Nesse sentido, focamos nosso olhar ao tratamento que é dado ao ensino da Matemática, em virtude de nossas percepções em relação aos sentimentos manifestados pelos alunos sobre a disciplina. Manifestam desejar aprender conteúdos, no entanto, paradoxalmente, manifestam sentimentos de insegurança e rejeição em perseguir esse objetivo. Tomamos essas manifestações como indícios de que a Matemática vem contribuindo claramente para a exclusão escolar, posto que ainda é um indicador presente na maioria das pessoas que se encontram excluídas socialmente em nosso País.

A expressão exclusão social por nós referida consiste em um processo sóciohistórico, por que passam indivíduos e grupos sociais, de distanciamento da vivência dos direitos, nos termos de Sposatti (1996) não se trata de um processo individual, embora atinja pessoas, mas de uma lógica que está presente nas várias formas de relações econômicas, sociais, culturais e políticas da sociedade brasileira. Esta situação de privação coletiva inclui pobreza, discriminação, subalternidade, não eqüidade, não acessibilidade, não representação pública.

Por considerarmos que a Educação consiste em um processo que constrói possibilidades de (re)inclusão escolar e social, buscamos estabelecer relação com a Educação de Jovens e Adultos - EJA como uma estratégia que pode favorecer a (re)inclusão escolar e a permanência com sucesso de jovens e adultos nessa modalidade de ensino, na perspectiva de se incluir socialmente, através da EJA.

Isto pode justificar nossa opção pela temática e pela metodologia de pesquisa, um estudo de caso - na modalidade investigativanarrativa em virtude da complexidade do tema que exige uma análise relacional entre os elementos que emergem a partir das vozes dos sujeitos constituindo uma teia de informações que se entrecruzam, fundamentada em proposições teóricas, reflexões e registros que a sustentam. Telles (2005) e Connelly \& Clandinin (1995).

Elegemos para explorar nesse artigo a metodologia de pesquisa que utilizamos e em linhas gerais os três núcleos de análise que orientaram a tessitura dessa trama narrativa, uma vez que compõem a tríade relacional aluno-professor-conhecimento, organizados nos seguintes eixos temáticos: 1) Alunos e alunas da EJA: sujeitos deste contexto, 2) A condução do processo de ensino e 
aprendizagem da matemática em classes da EJA e 3) Desafios do Ensino da Matemática de Jovens e Adultos no tempo presente.

\section{PRINCÍPIOS METODOLÓGICOS DA INVESTIGAÇÃO: PERCURSOS POR ONDE TRILHAMOS}

Por se tratar de um fenômeno complexo iniciamos nosso estudo por uma análise mais ampla do contexto sócio-econômico e históricocultural dos sujeitos envolvidos nesse estudo e da comunidade local que acolhe a escola. Voltamos nosso foco de análise para a escola lócus da investigação, na qual estivemos presente durante aproximadamente quatro meses acompanhando a dinâmica de seu funcionamento geral e, mais especificamente, a evolução de algumas aulas de matemática nas turmas de $3^{\mathrm{a}}$ e $4^{\mathrm{a}}$ etapas da Educação de Jovens e Adultos-EJA.

Tomamos, pois, esta escola como espaço real de pesquisa, definindo o processo de inclusão ou exclusão escolar e social como fenômeno enfocado na pesquisa. Por isso, buscamos desenvolver um estudo de caso - na modalidade investigativa-narrativa - que conforme nos ensina Telles (2005) se processa: ...Quando o professor-pesquisador deseja enfocar um determinado evento pedagógico, componente ou fenômeno relativo à sua prática profissional. Fundamentando-se na definição de Johnson (1992) diz que nos estudos de caso o pesquisador enfoca sua atenção para uma única entidade, um único caso, provindo de seu próprio ambiente profissional Os objetivos dos estudos de caso estão centrados na descrição e explicação de um fenômeno único isolado e pertencente a um determinado grupo ou classe.

Nesse estudo, orientamo-nos por procedimentos metodológicos numa lógica que rompe com o determinismo pré-concebido e durante o percurso da investigação as conexões de análise emergiram destacando os elementos que se entrelaçam e constituem uma teia de informações articuladas a partir de uma lógica relacional fundamentada em proposições teóricas, reflexões e registros bibliográficos que sustentam as análises desses elementos vários.

Durante o período em que estabelecemos algum tipo de interação com os professores, alunos e as equipes escolares, uma relação de cooperação entre nós foi estabelecida de forma tal que nos possibilitou um ir e vir em relação à construção dos relatos. Isto porque, em momento algum, nos foi negado esclarecimentos e emissão de opiniões sobre os temas em pauta e, da mesma forma, esse foi o nosso procedimento diante dessas equipes, interagindo com os sujeitos e com os processos de ensino e de aprendizagem. Ilustramos nossa atuação quando assumimos as duas turmas conduzindo as aulas nos dias em que os professores de matemática estiveram ausentes. A substituição docente nos oportunizou maior aproximação e conhecimento dos alunos bem como elementos para dialogarmos, posteriormente, com os professores.

Utilizamo-nos da narrativa, nos termos de Aragão (2004), como abordagem metodológica de pesquisa para reconstruir/transcrever as histórias vividas pelos alunos e professores em seus percursos escolares e formativos, as quais foram compartilhadas conosco, Além disso, utilizam-nos da narrativa para relatar os contextos e os processos de ensino e de aprendizagem desenvolvidos nas aulas de matemática, identificando elementos de análise que nos possibilitaram retomá-las e discuti-las, posteriormente, com os professores.

Os relatos, depoimentos, histórias de vida e manifestações de sentimentos na forma escrita e oral consistiram em riquíssimo material de pesquisa de onde emergiram os elementos de análise, uma vez que funcionam como contextos de produção de significados para os acontecimentos ocorridos na escola e na vida dos sujeitos envolvidos. As histórias narradas pelos professores, alunos e funcionários da escola são, ao mesmo tempo, método e objeto de pesquisa. (Cf.Telles, 2005).

Adotamos essa modalidade metodológica, por nos possibilitar interagir com os nossos sujeitos, não nos mantendo numa postura neutra, mas nos envolvendo e compartilhando experiências, interpretando, expondo, discutindo e buscando contrapontos na literatura, nos deixando livres para evidenciar os sentimentos e utopias sentidas e manifestadas em termos correspondentes aos mencionados por Gonçalves (T.V.O., 2000).

Encontramos em teóricos como Capra (1982), Morin (2004), Reigota (1998) e Santos (2003), um outro tipo de fomento que nos 
sustenta para tratar as questões emergentes numa dimensão relacional sistêmica e multidimensional, conduzindo nossa percepção sobre o objeto por nós constituído na sua totalidade. Isso implica dizer que não nos detivemos somente aos momentos pedagógicos de ensinamentos de matemática durante as aulas, mas ampliamos nosso foco de atenção para o funcionamento da escola como um todo, como se apresenta e se organiza na condição de espaço educacional, bem como voltamo-nos para as relações que nela se estabelecem, sua proposição político-pedagógica e as relações por ela estabelecidas com a comunidade em que está inserida. Ampliamos ainda mais nosso olhar analisando e levando em conta a dinâmica desse cenário maior que exerce decididas influências sobre a escola e os nossos alunos sujeitos desta pesquisa.

O nosso envolvimento nesses meandros metodológicos que caracterizam a pesquisa narrativa foi possível a partir de um processo organizativo e preparatório tendo em vista traçar um caminho para sentir o chão que iria trilhar. Um desses aspectos fundamentais consistiu em definir os sujeitos e demais elementos definindo pari pasu onde e quando poderia buscar informações e dados para identificar e caracterizar elementos ou indicadores de análise. A seleção de aspectos a serem observados e registrados foi se definindo à medida que o processo evoluía, na dinâmica do ir e vir, indagando, dialogando, entrevistando, ajustando e observando, quando necessário, para complementar nossos registros com base nas orientações pré definidas. Os elementos de análise que emergiram foram organizados didaticamente em três núcleos de análise que se integram e se interralacionam, e em linhas gerais apresentamos em seguida

\section{ALUNOS E ALUNAS DA EJA: SUJEITOS DESTE CONTEXTO}

Nesse primeiro núcleo de análise voltamos nossa atenção para os alunos e alunas de duas classes da EJA - da $3^{\mathrm{a}}$ e $4^{\mathrm{a}}$ etapas, devidamente matriculados na escola lócus deste estudo. Saber desses alunos e dessas alunas foi nossa primeira preocupação quando lá chegamos. Com suas devidas permissões após saberem do que se tratava essa pesquisa, procuramos saber quem eram, o que faziam além de estudar, por quais motivos optaram pela EJA; procuramos conhecer os seus sentimentos e as percepções de si, da escola e dos professores, especialmente os de matemática; quisemos saber suas compreensões do ensino da matemática, suas perspectivas de vida após a conclusão do Ensino Fundamental e até mesmo seus sonhos do futuro.

Nessa pesquisa mantivemos o propósito de fazer uma leitura positiva desses alunos, seguindo como Brunel (2004) uma das orientações de Charlot (2000) em relação aos estudos sobre alunos que sofreram alguma história de "fracasso na escola", que implicaram reprovação, "repetição de ano" ou abandono escolar. Tais características estão presentes nos alunos da EJA, razão pela qual vimos com o propósito de não só evidenciar seus "fracassos", deficiências e carências, mas com o intuito de conhecer esses alunos como pessoas e cidadãos.

Identificando os alunos sujeitos desse estudo: As duas classes sob consideração totalizam 99 alunos, dos quais 47\% são do sexo masculino e $53 \%$ são do sexo feminino. Apesar de terem sido matriculados 50 alunos numa classe e 49 na outra, a freqüência diária dos alunos atinge em média 32 alunos por classe e se todos freqüentassem as aulas a dimensão das salas de aula não suportaria esses quantitativos. Um indicativo de que os resultados dos censos escolares que são realizados de acordo com o número de matrículas efetivadas no início do ano letivo não correspondem aos alunos que estudam, como também revelam a concepção de que já se inicia o ano com a prerrogativa do fracasso escolar.

Embora os alunos, a direção e a secretaria da escola não saibam precisar o motivo pelo qual grande parte dos alunos deixam de freqüentar as aulas, relacionam as causas a um possível trabalho que o aluno faltoso poderia ter conseguido depois da matrícula, bem como remetem a problemas de trabalho, problemas familiares ou de saúde. A secretaria também levantou a hipótese (ou usou como evasiva) de que muitos se matriculam com interesse em conseguir tão somente a carteira de estudante para pagar 'meia passagem' em transporte urbano.

Em relação à faixa etária, este conjunto de alunos apresenta variação entre 15 e 62 anos de idade, com maior incidência de jovens entre 15 e 24 anos de idade, que equivalem a $71 \%$ dos alunos matriculados. Dentre esses jovens, 25\% 
deles ainda são adolescentes, pois se encontram na faixa etária entre 15 e 17 anos de idade. Essas duas classes refletem uma das mudanças e um dos novos desafios observados a partir de 1990 em relação ao público da EJA, uma vez que o público vem se constituindo com um perfil cada vez mais jovem, trazendo consigo novas demandas nos campos didático-metodológico, curricular, de conteúdos e espaços. Nesse sentido, Brunel (2004) desenvolveu um estudo sobre a temática do rejuvenescimento das turmas de EJA, onde encontramos ressonância para essa análise. Os jovens vêm encontrando na EJA uma forma de 'acelerar' o processo de conclusão do Ensino Fundamental, por se encontrarem 'atrasados nos estudos' como assim mesmo afirma a maioria dos jovens, em virtude principalmente de reprovações que sofreram nas séries anteriores e dos abandonos escolares efetivados.

Refletindo com a diretora da escola sobre essa questão, deparamo-nos, então, com outro elemento que mereceu nossa atenção, pois se refere aos procedimentos utilizados pela escola relativos a critérios de transferência de alunos do ensino regular diurno para as classes do turno noturno da EJA. Segundo a diretora da escola, os alunos são transferidos por 'serem mais velhos e muito desenvolvidos se comparados com os demais alunos'; diz que assim procede 'quando os alunos maiores aprontam alguma coisa durante o dia', referindo-se a algum ato de indisciplina por parte de um aluno com mais de 14 anos. As famílias dos adolescentes não são envolvidas nessas decisões tomadas, afinal, do seu ponto de vista, sua atitude representa "proteção" aos demais alunos. Com esse mesmo argumento de "proteção", nos disse que conversa muito com o pai ou mãe de alunos, tentando convencê-los do contrário (da não transferência para a EJA), quando estes vêm lhe pedir a 'transferência de um aluno muito bom que estuda de dia, para estudar na EJA à noite, por motivo de trabalho'.

São atitudes como essas que revelam nuances de punição ao aluno que é transferido compulsoriamente para a EJA, e nas duas situações revelam uma atitude clara de desvalorização e discriminação em relação à modalidade de ensino da EJA, assim como em relação ao seu público estudantil.

Relação com o trabalho: A maioria dos escola se desincumbem de uma carga horária de trabalho que varia entre 4 e 10 horas/dia. Em alguns casos chegam a extrapolar 10 horas de trabalho diário

De modo geral os alunos trabalhadores, desempenham ocupações pouco valorizadas, nas quais despendem muito tempo, muita energia e grande esforço físico. Razão pelas quais muitos chegam excessivamente cansados ou deixam de freqüentar as aulas devido a freqüentes atrasos de horário, dado que a escola desconsidera e não permite nem admite sua entrada se não no horário determinado. Sobre essa situação, um dos alunos da $3^{\mathrm{a}}$ etapa Rosivaldo de 36 anos - nos disse: 'Eu mesmo só estou freqüentando às aulas regularmente durante este mês, porque estou de férias do meu trabalho, mas quando recomeçar a trabalhar não comando mais o meu horário'. Esse aluno trabalha em uma madeireira e faz o carregamento dos navios, assim, sua liberação de fim de jornada depende da hora que conclui o carregamento. 'Acabo faltando às aulas e não é porque eu queira, é que tenho que optar entre a aula e o trabalho; acabo ficando com o trabalho, pois preciso trabalhar para sustentar minha família'. Como ele tantos outros nos disseram que apresentam dificuldades em compatibilizar o horário de aula com o de trabalho, por isso faltam, ou se chegam atrasados são impedidos de entrar na escola. Um impedimento burocrático sobremaneira desestimulante que os alunos vivenciam no cotidiano escolar de reinclusão.

A vida escolar desses alunos: Dos alunos respondentes ao questionário, $52 \%$ nunca parou de estudar, no entanto, encontram-se em defasagem de idade/série por duas razões, (1) ou iniciaram tardiamente os estudos, (2) ou foram reprovados durante o percurso escolar. Para $48 \%$ dos alunos essa situação soma-se com a de interrupções escolares, por terem sido levados a abandonar a escola.

Quanto aos motivos que levaram esses alunos a abandonar a escola por algum tempo, foram destacados pelas mulheres a gravidez precoce, o casamento e a necessidade de cuidar dos filhos. Citam ainda a necessidade de trabalhar para sustentar a família, mudanças de local de moradia, dificuldades financeiras, grande distância entre a escola e a residência, problemas de saúde, problemas familiares e 
pessoais, bem como as dificuldades de aprender (de decorar) e a falta de interesse (preguiça/brincadeiras), mencionada por úmero bastante reduzido.

Conforme registro dos 49 alunos que foram várias vezes reprovados, quando da indicação de qual havia sido a disciplina que mais os reprovou, as respostas incidiram sobre a disciplina 'matemática' que foi indicada por 13 alunos. A maioria dos alunos (30 alunos) não soube precisar em qual disciplina foram reprovados, em virtude de a reprovação ter ocorrido nas séries iniciais do Ensino Fundamental, razão que os levaram a repetir todas as disciplinas das respectivas séries nas quais vivenciaram essa experiência. A aluna Edilene que foi reprovada oito vezes em matemática na $1^{\mathrm{a}}$ série e duas vezes em matemática na $4^{\mathrm{a}}$ série, teve que repetir também todas as disciplinas tantas vezes quantas foi reprovada em matemática.

D. Firmina começou a freqüentar a escola com 59 anos e no relato de sua história de vida, fez a seguinte reflexão: É importante estudar porque uma pessoa que não sabe ler e nem escrever é uma pessoa 'cega'. Olha, quando eu não sabia nada... fico agora pensando... Quantas vezes eu peguei ônibus errado por que eu não sabia ler!? Quantas cartas eu deixei de ler e escrever!?... Então, a minha finalidade é aprender a ler bem e escrever!!!...Por isso estou nessa 'guerra', nessa 'luta' para aprender a ler e escrever. Usa a autoridade de sua idade e condição para apelar aos jovens: 'Também digo para vocês, jovens que ainda são, não abandonem os estudos, porque sem os estudos é muito difícil de viver. Eu lhes digo isso por experiência própria'. Este conselho Dona Firmina, com muita propriedade, dirigiu aos demais alunos que estavam conversando conosco em sala de aula sobre a importância de continuar estudando pela vida a fora, e os alunos a ouviam com respeito e com expressão reflexiva.

Percepções de si próprios: A autoimagem dos alunos configura o seu parâmetro de autovalorização, de auto-estima e de autoconfiança. O sentimento de confiança sobre si lhe possibilita mais facilmente superar as dificuldades e os desafios que se apresentam quando do seu retorno ao contexto escolar. Para esses alunos da EJA esses sentimentos apresentam-se abalados em virtude das condições limitadas da própria vida e das vivências escolares anteriores que não lhes foram agradáveis tais como as lembranças das reprovações, as determinações escolares ou sociais impondo as muitas desistências e gerando frustrações por não terem tido chances de estudar na infância e na adolescência.

São situações que alteram as energias de autoconfiança e de auto-estima e que podem criar bloqueios psicológicos de aprendizagem, justamente pela inibição da capacidade de criar, de conhecer, de estudar e de realizar, em muitos momentos influenciados pelos sentimentos adversos de incapacidade, de falta de confiança em si próprios, e de medo de se frustrar novamente.

A exaltação por parte da escola e dos próprios professores responsáveis pelas reprovações que promovem de que 'a culpa do insucesso escolar está unicamente nos alunos', faz com que essa idéia seja absorvida pelos alunos, comprometendo sua autoconfiança e auto-estima, mas resguardando a responsabilidade ou isentando de responsabilidade os demais sujeitos envolvidos no processo ensino-aprendizagem, como assim manifesta a aluna Joana, de 46 anos, aluna da $3^{\mathrm{a}}$ etapa da EJA: ...Eu não consigo aprender nada de matemática... nunca consegui!. O problema não está nos professores, eles explicam bem, eu é que não aprendo. Joana -46 anos.

São questões de ordem afetiva que se revelam por reações emocionais que podem criar bloqueios de aprendizagem que necessitam ser vencidos, daí a importância de o professor conhecer seus alunos especiais deste contexto, suas histórias de vida escolar e ter um olhar singular nessas situações. Em função das informações que obtiverem, podem procurar formas de contribuição, ao nível do ensino e da orientação pedagógica, para que os alunos superem essas dificuldades e encontrem nas aulas e na escola espaços de realização e de felicidade.

Para os jovens e adultos que buscam a EJA para concluir seus estudos, a escola tem um grande significado, ela funciona como um "portal" para a inclusão social, na perspectiva de uma vida melhor, uma vez que nas sociedades modernas o estudo passou a ser requisito primordial para conseguir um emprego, mesmo 
que nem sempre seja requisito suficiente para garantia de emprego. Os alunos perseguem esses objetivos, fazendo um grande esforço para freqüentar as aulas na escola, após uma longa jornada de trabalho, para perseguir e obter 'conquistas pessoais.

\section{A CONDUÇÃO DO PROCESSO DE ENSINO E APRENDIZAGEM DE MATEMÁTICA EDUCAÇÃO DE JOVENS E ADULTOS}

Privilegiamos nesse núcleo um professor de matemática da $4^{\mathrm{a}}$ etapa e uma professora de matemática da $3^{\mathrm{a}}$ etapa. Através de entrevistas, diálogos e observações de algumas de suas aulas destacamos os elementos de análise a partir de eixos temáticos, quais sejam:

Percepção de si próprios e de seus alunos: Nesse processo ficou marcada a dificuldade que os professores apresentam em fazer alguma auto-reflexão crítica sobre suas posturas nas relações interpessoais e didáticopedagógicas assumidas em suas aulas.

Transferem as dificuldades que sentem na condução do processo ensino-aprendizagem aos alunos ou ao processo organo-funcional da escola e do sistema educacional nos diversos âmbitos. Assim expressou um dos professores sobre a dificuldade que sente ao ensinar aos alunos da EJA que, para ele, se funda ...Na falta de conhecimento [matemático] dos alunos e na falta de base que apresentam. Os alunos, por sua vez, absorvem para si a responsabilidade de "seus insucessos e fracassos escolares", muito embora, ao nosso ver, estes na verdade não sejam deles.

Conduzir-se no processo de se perceber implica ao professor se dispor a fazer uma reflexão sobre si mesmo e sobre sua prática pedagógica. Nos termos de Arroyo (2004), o exercício de lembrar nossas próprias vivências... pode ser um bom exercício para melhor entender sua centralidade em nossa formação e até melhor entender os educandos.

No contexto da EJA, perceber os alunos como "alunos-problema" ou "fracassados", implica apostar em um novo "fracasso", que pode conduzir os alunos para uma nova desistência e, quem sabe, dessa vez para sempre excluídos da escola em virtude de que há sempre o risco de que seja quebrado ou desfeito um sonho. Brunel (2004).

Metodologias de ensino e abordagens adotadas: $\mathrm{Na}$ classe da $3^{\mathrm{a}}$ etapa, os alunos estavam estudando 'expressões numéricas com números naturais', em seguida, iniciaram os estudos sobre 'números inteiros relativos', através de incansáveis cópias de síntese dos conteúdos escritas no quadro de escrever pela professora, sem que houvesse qualquer explicação prévia. Copiavam durante mais de uma aula, sem nada compreender e resolviam em seguida repetidos exercícios. Uma aluna nos disse, ...não consigo copiar rápido do quadro e ao mesmo tempo prestar atenção para o que diz a professora.

O conteúdo de geometria foi abordado em um caderno/apostila sem que tivesse sido apresentado em sala de aula. Os alunos, por sua vez, diziam não compreender aquele assunto. ...Não entendo nada desses desenhos, nunca estudei isso, dizia um deles. A professora, por sua vez, nos explicou que tomou essa atitude porque não daria tempo de abordar o assunto em sala de aula, assim complementou ...O assunto está muito fácil de compreender é só ler com atenção... O problema é que eles têm dificuldade de leitura. Mesmo reconhecendo essa dificuldade a professora adotou essa metodologia criando um obstáculo didático para a aprendizagem desses novos conceitos de geometria. Pais (2001)

$\mathrm{Na} 4^{\mathrm{a}}$ etapa, os assuntos eram 'expressões algébricas' inicialmente, e em seguida 'polinômios'. Os dois professores utilizavam a mesma metodologia sendo que o professor da $4^{\mathrm{a}}$ etapa não interrompia as cópias ou explicações para contar 'causos' fatos ou fazer comentários como a professora da $3^{\text {a }}$ etapa assim procedia ; sua postura era de pouca conversa com os alunos posto que não havia interação entre eles. Por esse motivo, uma aluna em seus registros pediu que o professor olhasse para eles quando estivesse em sala de aula explicando algo. Em uma avaliação as questões sobre operações entre monômios foram ditadas e os alunos as escreviam de qualquer jeito, pois não estavam compreendendo esse assunto, não sabiam ainda registrar na linguagem matemática o que o professor estava ditando. Conseqüentemente como era de se esperar os resultados foram desastrosos. O professor nos mostrou as notas e 
comentou, 'veja só, eles não têm base nenhuma'.

Os alunos fazem um grande esforço para aprender, na tentativa de vencer as dificuldades, uma vez que acreditam que estas estejam centradas unicamente em si.

Os professores trabalham isoladamente e não dialogam entre si, não preparam planejamento e nem as aulas em curso, elegem de modo aleatório os conteúdos orientando-se por um livro ou dizem seguir uma programação proposta pela Secretaria de Educação.

Marcar a diferença e atuar com autonomia, implica em não nos pautarmos em conteúdos ou em séries, pré-definidos em currículos e confinados em 'grades', registrados nos livros e programações distribuídas pelas Secretarias de Educação entre as escolas.

?Caracterização das práticas pedagógicas de ensino e de aprendizagem: A partir de nossas observações e registros percebemos que as práticas pedagógicas desenvolvidas pelos professores de matemática da EJA, predominantemente, se caracterizam como "educação monocultural", uma vez que a abordagem dos conteúdos em aula se processa de maneira estática, reprodutivista, replicadora, repetitiva, conteudista, memorística e descontextualizada para os dias atuais. De outra forma, o conhecimento matemático é apresentado aos alunos como verdadeiro, inquestionável, imutável, a-histórico e a-crítico, pronto, acabado e definitivo (Cf. ARAGÃO, 2000). Além disso, as relações que se estabelecem são apenas formais porque impessoais, uma vez que faltam laços afetivos, falta aproximação, falta emoção, pontos considerados chaves, segundo Gasparetto (2000), para desencadear a motivação no aluno.

Práticas presentes no ensino de matemática que vêm sendo reproduzida entre os professores, promovendo grande prejuízo aos alunos pois prevalece uma aprendizagem mecânica de c onhecimentos que não são (re)recontextualizados, longe de desenvolver capacidades cognitivas, de análise e de crítica dos conhecimentos.

(Re)contextualizar o conhecimento científico implica em o professor saber traduzilo em uma linguagem apropriada para o ensino em sala de aula, de modo que faça sentido e seja compreensivo para as pessoas que estão envolvidas no processo ensino-aprendizagem. Nesse sentido, Stoer (1999) propõe que o professor selecione a parte mais importante do conteúdo. Para tanto, o professor define valores, objetivos e os métodos mais adequados ao grupo de alunos com quem irá atuar. Pais (2001) denomina transposição didática o estudo de como se processa essa escolha, bem como a definição de prioridades dos conteúdos para a educação escolar, referenciada na história das ciências e demais influências. Por maior que fosse o envolvimento e a vontade dos professores em propiciar aos alunos condições para aprenderem aqueles assuntos que estavam abordando, lhes faltava apropriação de outros conhecimentos docentes, para além dos específicos da disciplina.

\section{E S A F I O S D A E D U C A C Ã O MATEMÁTICA DE JOVENS E ADULTOS NO TEMPO PRESENTE}

As proposições definidas para a Educação de Jovens e Adultos, na perspectiva de exercer a função de reparação de um direito negado aos jovens e adultos excluídos do sistema escolar quando crianças e adolescentes, permeiam a Educação Matemática que nesse âmbito se realiza. Daí nosso propósito em abordar essa temática nesse estudo, tendo em vista fazer uma reflexão sobre as demandas e contribuições que o ensino da Matemática exerce na EJA.

Nos termos de Fonseca (1999), a interrupção ou o impedimento de suas trajetórias escolares não implica somente em um episódio isolado de não-acesso a um serviço, mas, num contexto mais amplo de exclusão social e cultural. No tempo presente encontram-se incluídos em um Programa Especial de Educação Básica, visando a continuidade ou a iniciação de seus estudos e que, em grande medida, condicionará também as possibilidades de re-inclusão que se forjarão nessa nova (ou primeira) oportunidade de escolarização. Motivo maior para que nós professores revisemos nossas práticas pedagógicas desenvolvidas junto a esse público específico e aqui nos detemos ao ensino de Matemática, que assume um papel de destaque na vida escolar desses alunos.

A partir de nossas vivências como professoras de alunos que apresentavam condições de vida pessoal e sócio-escolar semelhantes aos alunos da EJA, sujeitos desse 
estudo, com os quais tivemos oportunidade de vivenciar proposições pedagógicas e metodológicas da Educação Matemática, consideramos algumas propostas que parecem adequadas para esse contexto da EJA. Dentre esses paradigmas destacamos a Resolução de Problemas, a Modelagem Matemática, a Etnomatemática e outras Tendências atuais relativas ao ensino de matemática que dêem maior sentido ao que os alunos estão estudando. Consistem em ações educativas que se aproximam mais da condição social e cultural dos alunos, especialmente, por proporcionar a nós, educadores matemáticos, subsídios filosóficos e teórico-metodológicos que nos possibilitam compreender os alunos da EJA como sujeitos de conhecimento e aprendizagem.

Sentimentos dos alunos em relação aos professores de matemática e à própria disciplina: Pautadas nesse tipo de proposta, analisamos a manifestação dos sentimentos declarados pelos alunos em relação aos professores de matemática e à própria disciplina que marcaram e marcam suas trajetórias escolares. Cujo elemento destacado se refere ao tratamento que o professor lhes proporciona, principalmente atenção e paciência em relação às suas dificuldades de aprendizagem. Os alunos expressaram que o que qualifica um professor é a sua postura alegre, seu interesse pela matéria e o tratamento respeitoso que lhes dispensa quando the pedem uma explicação. Gostaria que o professor explicasse melhor e com calma, foi a manifestação de vários alunos. Principalmente daqueles que ainda apresentam muita dificuldade em relação à leitura e escrita. Não consigo copiar e prestar atenção ao que o professor fala, nos disse D. Firmina, ....as minhas colegas copiam para mim quando dá tempo.

Como professores de matemática precisamos compreender que a abordagem de conteúdos matemáticos não pode ser/estar desvinculada do processo de leitura e escritura. Nos termos postos por D'Ambrósio (2004), a escritura e a matemática se desenvolvem em simbiose, sob a influência de inúmeros fatores naturais e culturais. Portanto, há a necessidade de dispensar à matemática um tratamento de caráter inter-relacional com as demais formas de cultura, uma vez que se desenvolvem simultaneamente e se delineiam de acordo com suas especificidades e características próprias.
Conceber a matemática a partir de uma visão holística da história cultural implica para os professores construir estratégias de ação que possibilitem desenvolver um processo pedagógico de educação matemática com jovens e adultos, de modo a contribuir com a construção da autonomia desses alunos no desvencilhar das situações de suas vidas e lutas diárias.

Vale ressaltar que abordar a educação matemática de jovens e adultos, no âmbito escolar, nos remete a essa preocupação com sua dimensão utilitária, uma vez que, além de justificar o conhecimento matemático é oportuno, fornecer ao aluno adulto uma relação adulta com o objeto de conhecimento, algumas chaves de interpretação e produção de sentido, elementos indispensáveis na relação de ensinoaprendizagem permeada pelo respeito e espírito de construção da autonomia (Fonseca, 2004:28).

O lugar da Educação Matemática na (re)inclusão/exclusão social: Diante dos cenários de exclusão social em nosso país, nós professores de Matemática, não podemos perder de vista o que ressalta Aragão (2005:22), em relação à nossa postura profissional diante dos projetos políticos vigentes, quando nos ensina, que educar é sempre um ato político, sendo assim torna-se imprescindível definir nossa opção/posição se é a de reforçar as forças que lutam para perpetuar ou optar pelas forças que lutam para transformar as relações sociais em busca da emancipação e da liberdade.

Frente à essas questões, não se pode mais conceber que o ensino, especialmente o de matemática, enfatize unicamente a memorização, a reprodução ou replicação técnica de algoritmos, sem significado e sem compreensão, bem como conceba os educandos como meros receptáculos de informações. Essa prática, ainda se encontra muito presente nas classes da EJA, causando um grande prejuízo em relação à aprendizagem, além da dificuldade que se cria em relação à compreensão, por se tratar de conteúdos descontextualizados, desconexos e desatualizados. A aprendizagem memorística ou mecânica não contribui em quase nada para o desenvolvimento das capacidades cognitivas, de análise e de percepção crítica dos conhecimentos/conteúdos escolares. Impossibilita, pois, aos educandos a produção e a (re)significação de conhecimentos 
matemáticos, de forma tal que esses sejam úteis na conquista de uma vida de melhor qualidade.

No ensino de Matemática para jovens e adultos, precisamos não perder de vista as expectativas dos alunos, bem como, a garantia de um ensino de qualidade dos conteúdos abordados e necessários ao aluno, quer seja em relação aos correspondentes à etapa em curso quer seja os que lhes darão sustentação para a continuidade da escolaridade. Para tanto, não podemos perder de vista os parâmetros dos programas oficiais e a possibilidade de continuidade dos estudos. Dessa forma, assumimos com Fonseca (2002), o valor de uma reflexão que envolva alunos e professores na busca de definir o que seria essencial na Educação Matemática no nível do Ensino Fundamental e do Ensino Médio na EJA.

Vale ressaltar que na definição do essencial não podemos simplesmente eliminar conteúdos considerando unicamente o grau de dificuldade que apresentam para esse grupo. Pelo contrário, há necessidade de ser construída coletivamente uma programação cuja qualidade, seja tanto melhor na medida em que é consciente e honestamente elaborada e assumida por aqueles que se dispõem a desenvolvê-la.

Consideramos que uma proposição como essa se apresenta como viável para a formação dos professores de jovens e adultos, posto que pode contribuir para que, de forma amadurecida, se compreenda a importância de mudança de concepção em relação à definição de conteúdos, deixando de considerar o "que dá pra ensinar" de Matemática numa escola para Jovens e Adultos para buscar a inserção do ensino da Matemática na Educação Fundamental de pessoas jovens e adultas.

\section{À G ISA D E C O N C L U S Ã O : APRENDIZADOS QUE FICAM}

Nosso processo reflexivo nos proporcionou alguns aprendizados e ao nosso ver deixa o caminho aberto para outras reflexões imprescindíveis a essa temática.

Atuar na EJA exige de nós como profissionais atuantes na Educação um olhar especial e uma prática pedagógica realmente eficaz, impedindo que esses alunos jovens e esses adultos que buscam na escola uma via para sua (re)inclusão social venham a ser (re)excluídos desse Programa de Ensino, de forma tal que não consigam mais retornar.

Essa situação constitui um paradoxo nesse contexto de exclusão, uma vez que a escola representa para os jovens e adultos um espaço concreto um tipo de 'fortaleza' para abrigá-los e às suas lutas por inclusão social, no entanto, grande parte das escolas não se organiza nem social nem pedagogicamente para acolher os alunos da EJA, sendo assim corrobora com o processo de exclusão de seus alunos. O currículo escolar, via de regra, é desconectado das realidades, não levam em conta as necessidades dos alunos.

Por razões como essas, como professores de matemática não podemos perder de vista no nosso cotidiano escolar o importante aprendizado que se refere ao conhecimento sócio-antropológico de nossos alunos, favorecendo a (re)contextualização dos conhecimento. Os assuntos ou os temas das aulas quando apresentados da forma mais simplificada possível, contribui fortemente para a incompreensão de seus significados e a ausência total de sentido para o alunado. O que observamos é que na abordagem dos conteúdos deixava de haver qualquer preocupação com a seleção e a organização dos conteúdos, bem como predominava a simplificação de conceitos e de processos para 'não complicar' o aprendizado dos alunos.

Discorrer sobre os elementos que contribuem para a exclusão escolar dos alunos da EJA, por outro lado, implica sinalizar os elementos que contribuiriam para a inclusão social, neste caso analisado, uma vez que a relação inclusão-exclusão social se complementa e se imbrica justamente em função desses elementos.

A complexidade desse tema requer uma análise relacional entre os elementos que participam, mobilizam e promovem a exclusão escolar dos alunos, não podendo se restringir puramente ao ensino de matemática, como sendo o responsável único, mas ao conjunto de fatores que incidem sobre esse processo.

Há, portanto, necessidade de ampliar o raio de análise articulando questões mais amplas que enfrentam a educação e as políticas sociais em nosso País tais como (i) a criação de uma política nacional de educação de jovens e adultos, (ii) a definição do financiamento no orçamento 
público, (iii) a função social da escola, (iv) o sentido social do currículo, (v) critérios e formas diferenciadas no processo de avaliação e (vi) a formação de professores para trabalhar na EJA. Certamente, seriam aspectos como esses a serem considerados na construção de uma política educacional que tenha por objetivo a democracia, e a inclusão social e educacional de adolescentes, jovens e adultos.

\section{REFERÊNCIAS}

ARAGÃO, R.M.R. A investigação narrativa no âmbito da história oral de ações escolares de ensino e de aprendizagem em aulas. São Paulo: PPGE/UMESP, 2000.

BRUNEL, C. Jovens cada vez mais jovens na educação de jovens e adultos. Porto Alegre: Mediação, 2004.

CONNELLY, F. M. e CLANDININ, D.J. Relatos de Experiência e Investigatión Narrativa, IN: Larrosa, J. (org): Dejame que te cuente: ensayos sobre narrativa e educatión. Barcelona: Editorial Laertes, 1995.

D'AMBRÓSIO, U. Desafios da matemática no novo milênio. Palestra na I SIPEM. Educação Matemática em Revista, n. 11. dez/2001. São Paulo: Cortez, 2001.

FONSECA, Maria C. F. R. Educação matemática de jovens e adultos: especificidades, desafios e contribuições. coleção tendências em educação matemática. Belo Horizonte: Autêntica, 2002.

GASPARETTO, M.M. Ensino de matemática: Um processo excludente. In: BONETI, L.W. Educação exclusão e cidadania. 2.ed. Ijuí: UNIJUÍ, 2000. (Coleção Educação).

GONÇALVES, T. V. O. Ensino de ciências e matemática e formação de professores: marcas da diferença. Tese de Doutorado. Campinas: UNICAMP, 2000.

PAIS, L. C. Didática da matemática: uma análise da influência francesa. Belo Horizonte: Autêntica, 2001.

SPOSATI, A.O. Mapa da exclusão/inclusão social da cidade de São Paulo. São Paulo:Educ,1996.
STOER, Stephen R; MAGALHÃES, A. M; RODRIGUES, D. Os lugares da exclusão social: um dispositivo de diferenciação pedagógica. São Paulo: Cortez, 2004.

TELLES, J.A. É Pesquisa é? Ah, não quero, não bem!: Sobre Pesquisa Acadêmica e sua relação com a prática do professor de línguas. Linguagem e Ensino, vol.5, n.2, 2002 (91-116). Texto Internet rle.ucpel.tche.br/php/edições/v5 n2/f_joao.pdf. 
